\title{
Coping strategies of nursing students for dealing with stress in clinical setting: A qualitative study
}

Foozieh Rafati ${ }^{1}$, Esmat Nouhi ${ }^{2}$, Sakineh Sabzevari ${ }^{2}$, Nahid Dehghan-Nayeri ${ }^{3}$

${ }^{1}$ Ph.D. of Nursing, Faculty Member, Nursing and Midwifery School, Jiroft University of Medical Sciences, Jiroft, Iran

${ }^{2}$ Ph.D. of Nursing Education, Associate Professor, Department of Medical Surgical Nursing, Physiology Research Center, Nursing Research Center, Kerman University of Medical Sciences, Kerman, Iran

${ }^{3}$ Ph.D. of Nursing Education, Professor, Nursing and Midwifery Care Research Center, School of Nursing and Midwifery, Tehran University of Medical Sciences, Tehran, Iran

\section{Type of article: Original}

\begin{abstract}
Background: Nursing students in the clinical setting experience a high level of stress. The understanding of people involved in nursing education, from coping strategies of nursing students with clinical stress, is highly important for any kind of planning in this field

Objective: To explore the coping strategies of Iranian nursing students with stress in a clinical setting.

Methods: This qualitative content analysis study was carried out with twenty nursing students who were selected using purposive sampling at the Razi nursing and midwifery school in Kerman, in Iran during a ten-month period in 2016. Data were collected using semi-structured face to face interviews, and analyzed through Graneheim and Lundman's qualitative content analysis method.

Results: "Seeking well-being" as the main theme and three categories of "Active confrontation with stress", "mastering the mind and body" and "avoidance" were obtained from data analysis.

Conclusion: The exploration of nursing students' experiences of coping with clinical stressors, increases students' awareness of their coping strategy. The academic authorities in recognizing the coping strategies of students with stress in clinical setting, can provide necessary training on effective coping strategies for students.

Keywords: Coping behaviors; Stress; Nursing; Students
\end{abstract}

\section{Introduction}

Nursing students experience higher levels of stress than students in other health sciences. The clinical part of nursing education is more stressful than the theoretical part (1). A study in Bahrain found that all nursing students experienced moderate to severe stress in the clinical setting (2). Also, a conducted study in Iran revealed that 99.3 percent of nursing students reported the level of perceived stress as moderate to high (3). The common causes of clinical stress in nursing students included the fear of unknown events, working with equipment (4), staff and faculty incivility $(5,6)$, theory and practice gap (7), the fear of making a mistake (8) and communication with staff, peers and patients (9). Stress can lead to disease, changes in health, poor academic performance, students withdrawal from the program (10), and can ultimately affect the quality of patient care (11). Because nursing students are not able to avoid these stressors, it is necessary for students to cope with them, if they are not able to manage their stress, it will affect their performance, health, attitude and role satisfaction as a nurse (12). In a stress-adaptive strategy, the individual's ability to coping with stress is more important than the stress itself, Suitable coping methods reduce stress-induced injuries (13). Coping is a dynamic, behavioral and cognitive effort in controlling internal and external stress. There are at least two types of coping strategies; problem-focused and emotion-focused. Each individual uses one of the strategies depending on the type of threat, previous beliefs or impermanent factors such as changing

\section{Corresponding author:}

Assistant Professor Dr. Esmat Nouhi, Kerman University of Medical Sciences, Kerman, Iran.

Tel: +98.3431325219, Email: e_nuhi@kmu.ac.ir

Received: April 21, 2017, Accepted: August 20, 2017, Published: December 2017

iThenticate screening: August 21, 2017, English editing: September 25, 2017, Quality control: October 27, 2017

This article has been reviewed / commented by three experts

(C) 2017 The Authors. This is an open access article under the terms of the Creative Commons Attribution-NonCommercialNoDerivs License, which permits use and distribution in any medium, provided the original work is properly cited, the use is non-commercial and no modifications or adaptations are made. 
strategy based on type of feedback (14). Research has demonstrated that, nursing students employ a variety of coping strategies (15) such as; talking to friends, sports, crying, ignoring stress, feelings of sadness/misery and the use of alcohol, which may be adaptive or maladaptive (16). Some studies have pointed to problem solving as the most utilized strategy in nursing students (11). Others refer to emotion-focused coping methods, (17) while some believe that transference, optimism and problem solving are the most used strategies among nursing students (12). Since, coping strategies of nursing students affect their physical and mental health as well as the quality of care provided by them, identifying coping strategies of nursing students is important for early interventions (18). Coping must be examined in the context of dealing with a particular stress (19). Glazer and Gyuark recommend that qualitative studies be used to deeper and better understanding of coping strategies (20). Even though coping is a context-dependent phenomenon, studies on coping with stress by nursing students in clinical settings in Iran have been mostly quantitative, which used general questionnaires from other cultures, this methodology does not lead to a deep understanding of nursing students coping strategies. Besides, the researcher's experience, as a faculty member, indicate that some students experience a lot of stress in the clinical setting that limits their learning, this problem in addition to the literature gap in this field, motivated researchers to carry out a qualitative study in order to explore nursing students' coping strategies with clinical setting stresses in Iran. The nursing undergraduate program in Iran is a four-year-long nursing education, of which graduates will be awarded with a Bachelor's degree (BSc) certificate in nursing. During the first semester, students learn about the theoretical principles of basic nursing skills and practice clinical skills in a skill lab. Clinical training (practice placement) starts in the first year together with theoretical education, and continues until the end of the third year. In the fourth year, students spend internship in clinical setting, and work with nurses under head nurses and faculty supervision $(21,22)$. Nursing students in Iran are recruited according to ranking in the National Higher Education Entrance Examination, thus, students who have little or no information about nursing may be recruited. Often, they are not happy for not entering the nursing program.

\section{Material and Methods \\ 2.1. Study Design}

This qualitative study was carried out using a content analysis method to investigate nursing students' coping strategies with clinical stresses. Qualitative studies are utilized to increase understanding and describe the world of human experience (23). Content analysis is a systematic coding and categorizing approach which includes a process of understanding, interpreting and conceptualizing the essential meanings of qualitative data (24).

\subsection{Setting and Participants}

Study setting was Razi Nursing and Midwifery College and relevant settings as hospitals and dormitories in Kerman University of Medical Sciences in Iran that lasted ten months in 2016. The main study population comprised of undergraduate nursing students. Purposeful sampling was employed to recruit the participants. Inclusion criteria were: having at least a semester of clinical experience, the willingness to participate in the research and absence of previous clinical work experience. Participants with maximum variation in terms of gender, age, marital status, semester, and students' living condition (living in dormitory, with family or rented home) were selected. Data collection continued until data saturation was attained, which means, further interviews could not provide new information about the target concept. Data saturation was accrued after 18 interviews. Furthermore, two additional interviews were carried out to ensure data saturation.

\subsection{Ethical Consideration}

The Ethics Committee of Kerman University of Medical Sciences approved the study (ethics code: ir.kmu.rec.1394.575). All participants were informed about the aim and method of the research. Written informed consent was obtained from all participants prior to each interview. They were told that participation in the study and withdrawal from the study at any time was voluntary. They were assured of the anonymity and confidentiality of the study.

\subsection{Data Collection}

Initially, participants were visited or called and after explaining the aim of the study, the time and place of each interview was set. All interviews were carried out with participants' agreement at the Razi Nursing \& Midwifery School, in Kerman University of Medical Sciences. Data were gathered via face-to-face, in-depth interviews with semi- structured questions. Interviews explored issues surrounding clinical stressors, as well as coping strategies employed to deal with them. At the start of the interviews, the interviewer (first author who was not involved in teaching or evaluation of participants) started with general questions, and moved to more specific issues, such as; 
Tell me about your clinical experience, what are your experiences of clinical stressors? How do you deal with them? Proportional to the answers, probing questions were put forward, like "Could you explain more?" Interviews lasted between 45 to 75 minutes and were audio taped by a voice recorder device with participants' consent.

\subsection{Data Analysis}

Data was analyzed using qualitative content analysis method described by Graneheim and Lundman (25). Interviews were transcribed immediately after each interview. Initially, each text was read several times until a general impression was conceptualized. Thereafter, all texts were read line-by-line and were broken down into meaningful units which were key phrases in the text. Subsequently, the meaningful units were condensed and labeled with codes. Thereafter, the codes, according to similarities and differences, were allocated into subcategories. Similar subcategories were grouped into categories. Finally, the theme was determined as the expression of the latent meaning of the text. A sample of the process of analysis is shown in Table 1. MAXQDA12 software was employed for data analysis. Trustworthiness was assured via the use of Lincoln and Guba's criteria (26). To ensure credibility, long term involvement with participants was utilized, member check was used, which means, analyzed and interpreted data was shown to the participants to evaluate the interpretations made by the researcher and to make suggestions if they did not agree with them; however, they did agree with them. For conformability, two faculty members who had experience in performing qualitative research, confirmed data analysis. From the first interview, field notes were taken. To control dependability, supervisors revised the codes and categories in order to reach a consensus. For transferability, participants were selected with maximum variation, initial findings were given to several students who did not participate in the study, and they confirmed fitness of results with their experience. Also, thick description of data was carried out.

Table 1. Example of qualitative content analysis process

\begin{tabular}{|c|c|c|c|c|}
\hline Categories & Subcategories & Open code & $\begin{array}{l}\text { Condensed } \\
\text { Meaning units }\end{array}$ & Meaning units \\
\hline $\begin{array}{l}\text { Active } \\
\text { confrontation } \\
\text { with stress }\end{array}$ & $\begin{array}{l}\text { Improving } \\
\text { professional } \\
\text { competency }\end{array}$ & $\begin{array}{l}\text { Acquiring } \\
\text { necessary } \\
\text { knowledge to be } \\
\text { able to answer } \\
\text { patients' } \\
\text { questions }\end{array}$ & $\begin{array}{l}\text { Perhaps not } \\
\text { knowing how to } \\
\text { answer patients' } \\
\text { questions and } \\
\text { trying to learn the } \\
\text { most common } \\
\text { diseases }\end{array}$ & $\begin{array}{l}\text { When I am working on a ward, } \\
\text { I constantly worry that a patient } \\
\text { might ask me a question that I } \\
\text { do not know the answer to. So, } \\
\text { I try to learn about the most } \\
\text { common related cases when I } \\
\text { work on a ward. }\end{array}$ \\
\hline categories & $\begin{array}{l}\text { Correcting a } \\
\text { wrong } \\
\text { intervention }\end{array}$ & $\begin{array}{l}\text { Correcting the } \\
\text { mistake for a } \\
\text { patient }\end{array}$ & $\begin{array}{l}\text { Correction of } \\
\text { wrong procedure } \\
\text { for reducing stress }\end{array}$ & $\begin{array}{l}\text { The artery burst. I quickly took } \\
\text { off the tourniquet, I took out the } \\
\text { needle and applied some } \\
\text { pressure on the spot. I felt much } \\
\text { better when the bleeding } \\
\text { stopped. }\end{array}$ \\
\hline $\begin{array}{l}\text { Active } \\
\text { confrontation } \\
\text { with stress }\end{array}$ & $\begin{array}{l}\text { Facing stressful } \\
\text { situation } \\
\text { purposefully }\end{array}$ & $\begin{array}{l}\text { Decision making } \\
\text { while confronting } \\
\text { stressful situation }\end{array}$ & $\begin{array}{l}\text { Fear of rejection by } \\
\text { the patient and } \\
\text { deciding to } \\
\text { confront the patient }\end{array}$ & $\begin{array}{l}\text { I was afraid to introduce myself } \\
\text { to the patient, what if he ignores } \\
\text { me? But I pulled myself } \\
\text { together and entered the } \\
\text { patient's room. }\end{array}$ \\
\hline categories & $\begin{array}{l}\text { Reflecting on the } \\
\text { stressful situation }\end{array}$ & $\begin{array}{l}\text { Relieving the } \\
\text { stress by } \\
\text { analyzing the } \\
\text { situation }\end{array}$ & $\begin{array}{l}\text { Thinking about } \\
\text { stressful situations } \\
\text { and analyzing their } \\
\text { causes }\end{array}$ & $\begin{array}{l}\text { I go somewhere quiet and think } \\
\text { about the subject (stress) to find } \\
\text { out what happened, what should } \\
\text { I do? What should I have done } \\
\text { that I didn't? This way I resolve } \\
\text { the problem. }\end{array}$ \\
\hline $\begin{array}{l}\text { Active } \\
\text { confrontation } \\
\text { with stress }\end{array}$ & $\begin{array}{l}\text { The use of } \\
\text { communication } \\
\text { skills in } \\
\text { controlling } \\
\text { stressful } \\
\text { interactions }\end{array}$ & $\begin{array}{l}\text { Negotiations to } \\
\text { resolve stress }\end{array}$ & $\begin{array}{l}\text { Talking to the } \\
\text { supervisor about } \\
\text { the head nurse's } \\
\text { behavior }\end{array}$ & $\begin{array}{l}\text { Head nurse has treated me with } \\
\text { bad temper. I talked to my } \\
\text { supervisor about her. My } \\
\text { supervisor talked to head nurse } \\
\text { and solved my problem. }\end{array}$ \\
\hline
\end{tabular}




\section{Results}

Twelve females and 8 males that ranged in age between 18 to 35 years with mean 23 ( $\mathrm{SD} \pm 3.5$ ) participated in this study. Six of them were married and 14 were single. One main theme, three categories ("Active confrontation with stress", "mastering the mind and body" and "avoidance") and 15 subcategories emerged from data analysis (Table 2). "Seeking well-being" as the main theme was extracted from data analysis, this implies that participants employed varieties of coping strategies for approach to well-being. All participants' coping strategies were along the lines of reducing physical and mental symptoms of stress and attaining well-being. This theme included three categories: Active confrontation with stress, Mastering the mind and body and Avoidance.

Table 2. Emerged theme, categories and subcategories from data analysis

\begin{tabular}{|l|l|l|}
\hline Theme & Categories & Subcategories \\
\hline $\begin{array}{l}\text { Seeking } \\
\text { well being }\end{array}$ & $\begin{array}{l}\text { Active } \\
\text { confrontation with } \\
\text { stress }\end{array}$ & $\begin{array}{l}\text { Developing professional competence, correcting a wrong intervention, facing } \\
\text { stressful situations purposefully, reflection on stressful situations, the use of } \\
\text { communication skills in controlling stressful interactions }\end{array}$ \\
\cline { 2 - 3 } & $\begin{array}{l}\text { Mastering the } \\
\text { mind and body }\end{array}$ & $\begin{array}{l}\text { Deviation and stop thinking, realism, positive thinking, } \\
\text { relieving stress by doing favorite activities, the use of herbal and chemical } \\
\text { medicines, reducing physiological symptoms, releasing emotions, praying }\end{array}$ \\
\hline & Avoidance & Avoiding stressful situations, giving up \\
\hline
\end{tabular}

\subsection{Active Confrontation with Stress}

To control stress, some of the participants actively confronted the stressful situation and tried to deal with the situation this way.

\subsubsection{Developing Professional Competency:}

Given that one of the main causes of stress for the participants was their feeling on the lack of professional knowledge and skills, participants were trying to develop their knowledge and skills through various methods. Participants were developing their knowledge and skills via direct experience, observation of others, consultation with educators, staff, higher grade students and older classmates to become proficient in the procedures and patient care. In this regard, a male participant in the second semester (Participant No. 3) stated; "...I ask my practical questions from the nurses and theoretical questions from university teacher..." some participants were also using peer learning to develop their skills."... When classmates go to perform a procedure, I follow them to see how they do it..." said a female participant in the sixth semester (Participant No. 7). In order to cope better with environmental stress as well as upgrading their practical skills, the participants were developing their theoretical knowledge as well. One participant stated; "...I do not know many things, that is why when I go to a new ward, I study common clinical cases of the ward..." (A female participant in the eighth semester; Participant No. 4).

\subsubsection{Correcting a Wrong Intervention:}

When the source of stress was a wrong intervention for patients, the participants tried to prevent any harm to patients by quickly correcting their mistake, so as to be relaxed and have peace of mind. One of the female participants in the seventh semester said: "...While inserting a cannula, I entered into the artery by mistake. In this situation, you should do the best and fastest intervention. I took out the cannula and put a sterile pad on the spot and applied pressure on it. Literally, correcting the mistake reduced my stress..." (Participant No. 10).

3.1.3. Facing Stressful Situations Purposefully:

Some of the participants while facing stressful situations were trying to break the vicious cycle of avoidance-stress. One participant said: "...I tried to face the situation that I was escaping from. For instance, by standing next to my friend who was dealing with the same situation, I gradually tried to do it myself..." (A male participant in the fifth semester No 12). Another female student in sixth semester (Participant No. 7) said: "...I assessed it first (the patient's vein) then I faced my fear and entered the needle. I knew the more I hesitated, the more my stress would continue..."

\subsubsection{Reflection on Stressful Situations.}

This sub-category that was being used mostly by male participants refers to the analysis of stressful situations, thinking and mental rehearsal of the measures taken in the stressful situations. Students were reflecting on the stressful situations for two reasons; for analysis of the stressful situation and for mental rehearsal of the correct nursing care process to prevent the error. A male participant in this regard stated; "...I like to be alone and think about the subject (stressful situation), why this happened? Why was I treated like that? So that I can calm myself..." (Participant No. 13). Another male participant in the second semester who was stressed during clinical activities said: "...I do go and sit somewhere quiet and analyze the situation. I identify things that I should have done but didn't, thus subsequently, I would have a better performance if faced with similar situation..." (Participant No. 3). 


\subsubsection{The Use of Communication Skills in Controlling Stressful Interactions:}

When interacting with others (patients, staff, mentor, and peers) who could be stressful, participants employed their communication skills so as to control or prevent the stress. A male participant (No. 2) in this regard said: "...a patient might be angry and say something, I try to calm them down through a favorable eye contact or an appropriate verbal communication, and I don't allow patients to control my emotions..."Students stated that, they tried different ways to win the patients and families' trust so that they can allow the student to deliver care for them. "...I spoke to him (patient) and said that I am a nursing student, I am on my last semester and know what I am doing, then he allowed me collect his blood sample..." (Male participant in the eighth semester, No. 18).

\subsection{Mastering the Mind and Body}

To cope with stress alongside the use of mental activities such as; deviation and stop thinking, realism, and positive thinking, participants used strategies such as: performing favorite activities, taking drugs and medicines. They were also using techniques to decrease the physiological symptoms, releasing emotions, and praying to control their body and mind.

\subsubsection{Deviation and Stop Thinking:}

Some students using various methods such as "...engaging thought with something else..." (A male participant in the third semester, No. 20), diverted their mind from the stressful subject, or stopped stressful thoughts. One participant said: "...I said, it's enough, I will stop thinking about you (stressful thoughts) ..." (A female participant in the third semester, No 11).

\subsubsection{Realism:}

Some participants, by relying on existing realities, were coping with clinical setting stresses. They knew that, perfectionism can be highly maladaptive. One of the male participants in first semester said: "...I was stressed when checking patients' blood pressure, but then I said to myself, I am not supposed to know everything, this is my first semester and it is normal that I do not know many things. This way, I coped with the stress..." (Male participant in the first semester, No. 8).

\subsubsection{Positive Thinking:}

Positive thinking or repeating positive sentences were among methods used to cope with stresses. One of the male participants in this regard said: "...I repeated to myself that I could do it better than everybody else, and that was very helpful (in reducing the stress) ..." (Participant No. 8).

\subsubsection{Relieving Stress by Doing Favorite Activities:}

Most students were trying to distract their thoughts from stressful subjects by doing their favorite activities. "...We go out with our friends and have fun, in this way, we reduced our stress" (Female participant No. 14). Even one of the male participants in the first semester was using "cooking" to relieve the stress. "...I love cooking, when I get to the dormitory, in order to relieve the stress, I start cocking..." (Participant No. 3).

\subsubsection{The Use of Herbal and Chemical Medicines:}

A small number of participants used herbal or chemical medicines to deal with stress of the clinical environment. One female participant in the seventh semester said: "...When I have a presentation the next day, and the teacher is strict, I make myself a glass of milk with cinnamon or brew borage, then I feel much better..." (Participant No 10). Another male participant in the fifth semester said: "...In the morning, I will say another day has begun, patients, professors and peers' demand again, so I take an Inderal pill to calm myself down a bit and then go to work in the clinical setting" (Participant No. 1). The same student also said: "...When one of my friends comes to the dormitory from practicum, he smokes to lower his stress, and when I object to his attitude, he says, smoking to me is like chewing gum for you..."

3.2.6. Reducing Physiological Symptoms:

Few of the participants were using techniques such as; deep breathing, drinking water or resting to reduce the physiological symptoms of stress. "...My heart was palpitating and I was also breathing fast, I said to the patient that I needed to go out of the room to wash my hands, thereafter I came out and took a couple of deep breaths to normalize my breathing rhythm" (Male participant in the first semester, No 8).

\subsubsection{Releasing Emotions:}

Some of the participants were relaxing themselves by talking to others about stressful events. Most of the participants were talking to peers, family members and even mentors for catharsis of their emotions. One female participant in the fifth semester talked about her experience of peace by talking to her husband and said: "...Basically, when I have a stressful situation at my practicum, I go home and talk to my husband and that makes me relaxed and calm" (Participant No. 9). 


\subsubsection{Praying:}

Strategy used by few participants was praying. Praying impacted on participants' perceptions of stressful situations, rather than reduce stress symptoms. "...I pray and say to myself that God willing, I'll succeed (in patient care)" (Female participant in the third semester, No 19).

\subsection{Avoidance}

As seen from all the statements of the participants, avoidance was the most used strategy.

\subsubsection{Avoiding Stressful Situations:}

Participants believed that this strategy was effective in some stressful situations and they were trying to avoid stressful people and situations. "...I'm stressed while taking blood samples, I'm afraid, so I ask others to do it for me..." (Male participant in the 5th semester, No 12). Another female participant in the sixth semester talked about avoidance of individuals: "... I picked up some gloves to take blood samples with a nurse, but she said: one glove is enough. She wanted to take blood samples with only one glove. It was hard and unbearable for me; but I could not protest. I was just a student; so, I did not argue with him... "(Participant No. 17).

3.3.2. Giving up:

In cases where the stressful situation was outside the control of students, they give up to prevent stress. They avoid mentally stressful situations with these manners. One female student in the fourth semester said: "...She (head nurse) told me to check the vital signs of 40 patients on the ward, it was tiring but I didn't have a choice, I did it because she was the evaluator of my practice..." (Participant No. 15).

\section{Discussion}

The results of this study showed that, nursing students were using a variety of strategies to cope with work-related stress in the clinical setting. To actively deal with the clinical setting's stress, participants used strategies to develop their professional competency, correct their mistakes, confront stressful situations, and reflect on stressful issues. Development of professional competency was one of their most important strategies for coping with the stress of the clinical environment. Due to lack of knowledge or confidence in their professional skills, participants were faced with stress throughout their entire academic education; hence they recognized the development of professional competency as a problem-based solution in dealing with their stress. Therefore, clinical instructors should create an atmosphere in which nursing students express their skill in conducting procedures without fear of instructors' judgment, and in which instructor's support students in the process of gaining professional competency. Also in a study by Dadgaran et al, the development of practical skills was recognized as one of the ways of gaining professional competency by Iranian nursing students (27). Rapid correction of incorrect action by students, showed the importance of patient safety for them. Therefore, nursing students need to be trained on patient safety and risk management as a preventive coping, before entering to the clinical setting. Researchers in this regard state that to identify threats of patient safety, incorrect reports and understanding of errors' consequences in Iran's nursing education, there is need for a fundamental change in educational philosophy towards empirical and reflective learning (28) and also in curriculum content. Furthermore, to achieve professional maturity, some students were facing stress purposefully in stressful interventions. They state that they can never deal with stressful situations by running away from them. This finding is consistent with the theme "Struggle for clinical independency" in the study by Dadgaran et al. (27). Nursing students knew that direct participation in activities and techniques of nursing practice can lead to a more stable learning (29).

The participants of this study, by reflecting and thinking carefully on their behavior and behavior of others in stressful situations with careful analysis of the situation, learned to deal with the situation or increase their knowledge and skills. A detailed analysis of stressful situation was carried out alone or with the help of peers. This finding is consistent with the findings of Reev et al. (16) and Sun et al. (6) studies. Ganzer and Zauderer also stated that, reflection enhanced students' self-awareness and ability to adapt mentally with the experiences of the psychiatric ward (30). Since reflection helps students better understand the stressful situation, gain self-awareness, and improve the ability to solve a problem, so it can be taught to them as an effective coping strategy by instructors. Moreover, participants were managing stressful interactions to reduce their stress. Also, by using this technique, they were trying to win patients and their family's trust. Due to staff shortages, students in Iran undertake almost all nursing procedures, they know that winning a patients' trust is the key in caring for them. Particularly, after enacting a general health insurance by Iran's previous government, hospital admission has not been proportionate to the increase of nursing staff, and this resulted in nursing students undertaking most procedures. Also in Hartman's study, most participants believed that good interpersonal communication is needed to resolve the conflict in the clinical setting (31). Also, the emerged theme in the study by O'Mara et al. was "rebuilding relationship" to face 
communication challenges (32). Having control over the body and mind was another category mentioned by the participants. To control their mental and physiological functions, students undertook a series of actions. Findings regarding the use of thought's distraction techniques are consistent with the findings of Phillips (33) and Al- Zayyat and Al-Gamal (34). To better cope with environmental stress, some of the students chose to be realists and set realistic professional goals. They were also avoiding unrealistic perfectionism. Maladaptive perfectionism is related to unhealthy work and psychological consequences. Moreover, nurses who have maladaptive perfectionism may feel depressed and not supported, which could lead to their inability to learn from mistakes (35). Results of this study regarding the use of positive thinking is consistent with the findings of Wolf's study (36). Positive thinking does not change the actual situation of a stressful situation but changes the person's interpretation of the position. Students also, by doing their favorite activities, reduced their stress. In a study by Sun, students listened to music and watched TV to free their minds from anxiety (6).

The use of herbal and chemical medicines was another way some students used to manage stress-induced physiological and psychological symptoms. In this study, only two students referred to smoking marijuana and cigarettes, and no student used alcohol. In the study of Seyedfatemi et al. in Iran, over $90 \%$ of the participants declared that, they avoided strategies such as; smoking or drinking beer or wine to reduce stress (37). Avoiding the consumption of alcohol by the participants of this study could be related to religious and legal barriers, regarding the use of alcohol in Iran. Results of this study on alcohol consumption are against the findings in the study of Reev et al. (16). This difference might be related to religious and cultural differences. The use of herbal medicines by some participants in reducing stress is related to the view of Iranian society that believes in low toxicity and side effects of herbal medicines. Khorasgani and Moghtadaie's study showed that the view of Iranian nursing students on Iranian traditional medicine is positive (38). In this study, few of the students used procedures such as; deep breathing, relaxation and drinking water to reduce the physiological symptoms of stress. Which indicates that they are not familiar with such techniques, therefor, teaching non-pharmacological techniques to nursing students for reducing their stress symptoms is necessary. Literature indicates that special breathing exercises are effective in reducing symptoms of stress, anxiety and insomnia (39). Releasing emotions associated with stress by talking to others is a strategy that has also been confirmed by other studies $(6,15,33)$. Peers and instructors as available social support resources, can play a more active role in nursing students' coping of stress. The results of the study revealed that few participants benefit from praying when encountering stressful situations, perhaps their experience is not as intense as to require prayer and spirituality. Paying attention to prayer has been confirmed in other Asian countries $(12,15)$. Avoiding and escaping from stressful situations, was the most widely utilized strategy in coping with the stress of the clinical environment. This finding has been confirmed by O'Mara et al. (32). Studies by Shaban et al. (11) and Zhao et al. (12), showed that avoidance was the least used strategy among students for coping. The differences in these findings could be attributed to the differences in participants, culture or method of research. Unfortunately, avoidance reduces stress temporarily, therefore, instructors should be careful about avoiding adaptive strategy in nursing students. In cases where students cannot find any solution for their problem, they give up and accept it. Probably, lack of meaningful personal relationships in the clinical environment leads to increased dependency behaviors such as, incontestable agreement with the decision made by others and surrendering. Generalizability due to the low number of participants, selecting them from one university, and the nature of the study may be the limitations.

\section{Conclusions}

According to this qualitative study, nursing students apply different coping strategies, depending on the contextual condition. In order to solve stressors, they tried to confront stressful sources actively, sometimes they were looking for a way to reduce their physical, psychological, and cognitive symptoms caused by stress, other times, when they felt the stressful situation was beyond their control, they avoided or accepted it. According to the findings, planning and adoption measures to nursing students training for active coping strategies, improving positive methods for reducing stress symptoms and helping to eliminate maladaptive coping strategies as drug consumption and avoidance by instructors and authorities is probably effective in nursing students coping with clinical stresses. Action research and quantitative studies in this field are a good route for future research.

\section{Acknowledgments:}

The authors would like to thank nursing student participants and research and ethic board members of Kerman University of Medical Sciences. This study was part of a nursing $\mathrm{PhD}$ dissertation and was supported financially by Kerman University of Medical Sciences. It was coded as 94/518. 


\section{Conflict of Interest:}

There is no conflict of interest to be declared.

\section{Authors' contributions:}

All authors contributed to this project and article equally. All authors read and approved the final manuscript.

\section{References:}

1) Labrague LJ. Stress, stressors, and stress responses of student nurses in a government nursing school. Health Sci J. 2013; 7(4): 424-35.

2) John B, Al-Sawad M. Perceived stress in clinical areas and emotional intelligence among baccalaureate nursing students. Journal of the Indian Academy of Applied Psychology. 2015; 41(3): 75-84.

3) Pourafzal F, Seyedfatemi N, Inanloo M, Haghani H. Relationship between perceived stress with resilience among undergraduate nursing students. Hayat. 2013; 19: 41-52.

4) Pulido - Martos M, Augusto - Landa JM, Lopez - Zafra E. Sources of stress in nursing students: a systematic review of quantitative studies. International Nursing Review. 2012; 59(1): 15-25. doi: 10.1111/j.1466-7657.2011.00939.x.

5) Lasiter S, Marchiondo L, Marchiondo K. Student narratives of faculty incivility. Nursing outlook. 2012; 60(3): 121-6. doi: 10.1016/j.outlook.2011.06.001. PMID: 21840556.

6) Sun FK, Long A, Tseng YS, Huang HM, You JH, Chiang CY. Undergraduate student nurses' lived experiences of anxiety during their first clinical practicum: A phenomenological study. Nurse Educ Today. 2016; 37: 21-6. doi: 10.1016/j.nedt.2015.11.001. PMID: 26615773.

7) Scully NJ. The theory-practice gap and skill acquisition: An issue for nursing education. Collegian. 2011; 18(2): 93-8. doi: 10.1016/j.colegn.2010.04.002. PMID: 21706997.

8) Driscoll R, Evans G, Ramsey G, Wheeler S. High Test Anxiety among Nursing Students. 2009. Available from: http://files.eric.ed.gov/fulltext/ED506526.pdf.

9) McKenna L, Plummer V. Indonesian student nurses' perceptions of stress in clinical learning: A phenomenological study. Journal of Nursing Education and Practice. 2013; 3(5): 56-65. doi: 10.5430/jnep.v3n5p56.

10) Delaney C, Barrere C, Robertson S, Zahourek R, Diaz D, Lachapelle L. Pilot Testing of the NURSE Stress Management Intervention. Journal of Holistic Nursing. 2016; 34(4): 369-89. doi: 10.1177/0898010115622295. PMID: 26721516.

11) Shaban IA, Khater WA, Akhu-Zaheya LM. Undergraduate nursing students' stress sources and coping behaviours during their initial period of clinical training: A Jordanian perspective. Nurse Education in Practice. 2012; 12(4): 204-9. doi: 10.1016/j.nepr.2012.01.005. PMID: 22281123.

12) Zhao FF, Lei XL, He W, Gu YH, Li DW. The study of perceived stress, coping strategy and self - efficacy of Chinese undergraduate nursing students in clinical practice. Int J Nurs Pract. 2015; 21(4): 401-9. doi: 10.1111/ijn.12273. PMID: 24750234.

13) Shriver CB, Scott-Stiles A. Health habits of nursing versus non-nursing students: A longitudinal study. J Nurs Educ. 2000; 39(7): 308-14. doi: 10.3928/0148-4834-20001001-06. PMID: 11052653.

14) Lazarus RS. Coping theory and research: past, present, and future. Psychosomatic medicine. 1993; 55(3): 234-47. doi: 10.1097/00006842-199305000-00002. PMID: 8346332.

15) Jan LK, Popescu L. Israel's Nursing Students' Stress Sources and Coping Strategies During Their First Clinical Experience in Hospital Wards-A Qualitative Research. Revista de Asistenta Sociala. 2014; (4): 163.

16) Reeve KL, Shumaker CJ, Yearwood EL, Crowell NA, Riley JB. Perceived stress and social support in undergraduate nursing students' educational experiences. Nurse Education Today. 2013; 33(4): 419-24. doi: 10.1016/j.nedt.2012.11.009.

17) Fornés-Vives J, Garcia-Banda G, Frias-Navarro D, Rosales-Viladrich G. Coping, stress, and personality in Spanish nursing students: A longitudinal study. Nurse education today. 2016; 36: 318-23. doi: 10.1016/j.nedt.2015.08.011.

18) Ni C, Lo D, Liu X, Ma J, Xu S, Li L. Chinese female nursing students' coping strategies, self-esteem and related factors in different years of school. Journal of Nursing Education and Practice. 2012; 2(4): 33. doi: 10.5430/jnep.v2n4p33.

19) Folkman S, Lazarus RS. If it changes it must be a process: study of emotion and coping during three stages of a college examination. J Pers Soc Psychol. 1985; 48(1): 150. doi: 10.1037/0022-3514.48.1.150. PMID: 2980281. 
20) Glazer S, Gyurak A. Sources of occupational stress among nurses in five countries. International Journal of Intercultural Relations. 2008; 32(1): 49-66. doi: 10.1016/j.ijintrel.2007.10.003.

21) Dinmohammadi M, Jalali A, Peyrovi H. Clinical learning experiences of Iranian student nurses: A qualitative study. Nursing Practice Today. 2016; 3(1): 31-9.

22) Peyrovi H, Yadavar - Nikravesh M, Oskouie S, Berterö C. Iranian student nurses' experiences of clinical placement. Int Nurs Rev. 2005; 52(2): 134-41. doi: 10.1111/j.1466-7657.2005.00417.x. PMID: 15842326.

23) Holloway I, Wheeler S. Qualitative research in nursing and healthcare. John Wiley \& Sons; 2013.

24) Holloway I. Qualitative research in health care. McGraw-Hill Education (UK); 2005.

25) Graneheim UH, Lundman B. Qualitative content analysis in nursing research: concepts, procedures and measures to achieve trustworthiness. Nurse Educ Today. 2004; 24(2): 105-12. doi: 10.1016/j.nedt.2003.10.001.

26) Lincoln YS. Guba EG. Naturalistic inquiry. Newbury Park, CA: Sage; 1985.

27) Dadgaran SA, Parvizy S, Peyrovi H. Passing through a rocky way to reach the pick of clinical competency: A grounded theory study on nursing students' clinical learning. Iran J Nurs Midwifery Res. 2012; 17(5): 330-7. PMID: 23853644, PMCID: PMC3703072.

28) Vaismoradi M, Bondas T, Jasper M, Turunen H. Nursing students' perspectives and suggestions on patient safety--implications for developing the nursing education curriculum in Iran. Nurse Educ Today. 2014; 34(2): 265-70. doi: 10.1016/j.nedt.2012.10.002. PMID: 23116928.

29) Baraz S, Memarian R, Vanaki Z. The diversity of Iranian nursing students' clinical learning styles: A qualitative study. Nurse Educ Pract. 2014; 14(5): 525-31. doi: 10.1016/j.nepr.2014.03.004. PMID: 24731951.

30) Ganzer CA, Zauderer C. Structured learning and self-reflection: Strategies to decrease anxiety in the psychiatric mental health clinical nursing experience. Nurs Educ Perspect. 2013; 34(4): 244-7. doi: 10.5480/1536-5026-34.4.244. PMID: 24187728.

31) Hartman RL, Crume AL. Educating nursing students in team conflict communication. Journal of Nursing Education and Practice. 2014; 4(11): 107. doi: 10.5430/jnep.v4n11p107.

32) O'Mara L, McDonald J, Gillespie M, Brown H, Miles L. Challenging clinical learning environments: Experiences of undergraduate nursing students. Nurse education in practice. 2014; 14(2): 208-13. doi: 10.1016/j.nepr.2013.08.012.

33) Phillips JK. Exploring student nurse anesthetist stressors and coping using grounded theory methodology. AANA J. 2010; 78(6): 474-82. PMID: 21309295.

34) Al - Zayyat AS, Al - Gamal E. Perceived stress and coping strategies among Jordanian nursing students during clinical practice in psychiatric/mental health courses. Int J Ment Health Nurs. 2014; 23(4): 326-35. doi: 10.1111/inm.12054. PMID: 24372812.

35) Chang Y. The relationship between maladaptive perfectionism with burnout: Testing mediating effect of emotion-focused coping. Personality and Individual Differences. 2012; 53(5): 635-9. doi: 10.1016/j.paid.2012.05.002.

36) Wolf L, Stidham AW, Ross R. Predictors of stress and coping strategies of US accelerated vs. generic Baccalaureate Nursing students: an embedded mixed methods study. Nurse Educ Today. 2015; 35(1): 201 5. doi: 10.1016/j.nedt.2014.07.005. PMID: 25127928.

37) Seyedfatemi N, Tafreshi M, Hagani H. Experienced stressors and coping strategies among Iranian nursing students. BMC Nurs. 2007; 6: 11. doi: 10.1186/1472-6955-6-11. PMID: 17999772, PMCID: PMC2203983.

38) Khorasgani SR, Moghtadaie L. Investigating Knowledge and Attitude of Nursing Students Towards Iranian Traditional Medicine Case Study: Universities of Tehran in 2012-2013. Glob J Health Sci. 2014; 6(6): 16877. doi: 10.5539/gjhs.v6n6p168. PMID: 25363119, PMCID: PMC4825501.

39) Brown RP, Gerbarg PL, Muench F. Breathing practices for treatment of psychiatric and stress-related medical conditions. Psychiatr Clin North Am. 2013; 36(1): 121-40. doi: 10.1016/j.nepr.2007.04.003. PMID: 23538082. 